\title{
Impact of Iron Status on Thyroid Function: A Community Based Cross Sectional Study in Eastern Nepal
}

\author{
Saroj Thapa, ${ }^{1}$ Madhab Lamsal, ${ }^{2}$ Rajendra K. Chaudhari, ${ }^{2}$ Basanta Gelal, ${ }^{2}$ Sanjay Kumar Sah, ${ }^{3}$ Saroj \\ Kunwar, ${ }^{4}$ Nirmal Baral ${ }^{2}$ \\ ${ }^{1}$ Department of Biochemistry, Kathmandu University School of Medical Sciences, Dhulikhel, Nepal, ${ }^{2}$ Department of \\ Biochemistry, BP Koirala Institute of Health Sciences, Dharan, Nepal, ${ }^{3}$ Department of Biochemistry, National Medical \\ College, Birgunj, Nepal, ${ }^{4}$ Department of Biochemistry, Modern Technical College, Lalitpur, Nepal.
}

\begin{abstract}
Background: Iron deficiency is the most common nutritional deficiency in the world. The relation between thyroid hormones and iron status is bidirectional. The aim of this study was to assess iron nutrition status and evaluate its relationship with thyroid hormone profile among children of Eastern Nepal. Methods: A community based cross-sectional study was conducted in eastern Nepal. A total of 200 school children aged 6-12 years were recruited after taking informed consent from their guardians. Blood samples were collected and assayed for free thyroid hormones $\left(\mathrm{fT}_{3}\right.$ and $\left.\mathrm{fT}_{4}\right)$, thyroid stimulating hormone $(\mathrm{TSH})$, serum iron, total iron binding capacity (TIBC) concentration and percentage transferrin saturation was calculated. Results: The mean serum iron and TIBC was $74.04 \mu \mathrm{g} / \mathrm{dl}$ and $389.38 \mu \mathrm{g} / \mathrm{dl}$ respectively. The median transferring saturation was $19.21 \%$. The overall prevalence of iron deficiency (Transferrin saturation $<16 \%$ ) was $34 \%$ $(\mathrm{n}=68)$. The mean concentration of $\mathrm{fT}_{3}$ and $\mathrm{fT}_{4}$ was $2.87 \mathrm{pg} / \mathrm{ml}$ and $1.21 \mathrm{ng} / \mathrm{dl}$ respectively, while the median TSH concentration was $3.03 \mathrm{mIU} / \mathrm{L}$. Median TSH concentration in iron deficient group $(3.11 \mu \mathrm{g} / \mathrm{dl})$ and iron sufficient group $(2.91 \mu \mathrm{g} / \mathrm{dl})$ was not significantly different. Among iron deficient children $5.9 \%$ had subclinical hypothyroidism $(n=4)$. Iron status indicators were not significantly correlated with thyroid profile parameters in the study population. Conclusions: The prevalence of iron deficiency is high and iron deficiency does not significantly alter the thyroid hormone profile in the study region.
\end{abstract}

Keywords: iron deficiency; thyroid hormones; school children; subclinical hypothyroidism.

\section{INTRODUCTION}

Iron is a critical element in the function of all cells. Iron deficiency is the most common nutritional deficiency in the world and remains a major public health problem particularly in developing countries. It adversely affects growth, development and alters the physiology of thyroid. ${ }^{1}$

The relation between thyroid hormones and iron status is bidirectional. Thyroid hormones increase iron absorption and incorporation into erythrocytes, whereas iron deficiency impairs thyroid hormone secretion and metabolism. ${ }^{2}$ Severe iron deficiency could interfere with thyroid hormone synthesis and decrease the thyroperoxidase activity. ${ }^{3}$ It may also reduce circulating levels of $\mathrm{T} 4-5$, deiodinase, resulting in diminished conversion of $\mathrm{T} 4$ to $\mathrm{T} 3{ }^{4}$

There are mixed evidences from various part of world relating iron status and thyroid profile. The aim of the present study was to assess iron nutrition status and evaluate its relationship with thyroid hormone profile among school children of eastern Nepal

\section{METHODS}

A cross sectional study was conducted in Udayapur District situated in Eastern part of Nepal from August 2014 to July 2016. Udayapur district has diverse geographical and socioeconomic variations. Primary school children (6 years to 12 years) were enrolled in this study from three schools. Two schools were selected from terai (plain) belt whereas one school was from the hilly region. We randomly selected 200 healthy school going children after excluding those children taking drugs that interfere with thyroid function and those having chronic illness. Sample size was calculated on the basis of latest prevalence of iron deficiency in Nepal (prevalence of iron deficiency $=36 \%$, $95 \%$ confidence interval, $80 \%$ power). ${ }^{5}$ Informed written consent was obtained from the guardians of respective participating children. $3 \mathrm{ml}$ of venous

Correspondence: Dr. Saroj Thapa, Department of Biochemistry, Kathmandu University School of Medical Sciences Dhulikhel, Nepal. Email: drsarojthapa@gmail.com. Phone: +977-9841276674.DOI: DOI 10.3126/cmsn.v15i1.21022. Article received: 2018-09-06. Article accepted: 2018-12-30. 
blood sample was collected from the participants. Samples were refrigerated at $-20^{\circ} \mathrm{C}$ until analysis. The ethical clearance for this study was given by the Institutional Review Board of B P Koirala Institute of Health Sciences (BPKIHS), Dharan.

Serum iron, Total iron binding capacity (TIBC) and percentage transferrin saturation was used as an indicator of iron status. Similarly, serum thyroid hormones i.e free tri-iodothyronine (fT3), free thyroxine (fT4) and thyroid stimulating hormone (TSH) were used as an indicator of thyroid function status. Serum iron and TIBC was measured by colorimetric method using commercial kit manufactured by Human GmbH, Germany. We used percentage transferrin saturation as an indicator of iron deficiency. Children with saturation $<16 \%$ were considered iron deficient. ${ }^{1}$ Measurements of serum fT3, fT4 and TSH was carried out using ELISA commercial Kit from Diametra. Normal reference range for thyroid hormones were fT3 $(1.2-4.2 \mathrm{pg} /$ $\mathrm{ml})$, fT4 (0.8- $2.2 \mathrm{ng} / \mathrm{dl})$ and TSH (0.39-6.16 mIU/L) according to kit manufacturer. Participants were classified as euthyroid, subclinical and overt hypo and hyperthyroid based on the thyroid hormone results.

The data generated from the study was entered in Microsoft excel 2013 and analysed using SPSS version 21.0. Continuous variables was expressed as mean $\pm \mathrm{SD}$ or median (IQR) according to the distribution of the data. The categorical variables was expressed as number (percentage). Independent $\mathrm{t}$ test, one way ANOVA, Man whitney test and kruskal Wallis test was applied according to the distribution of the data. Pearson and Spearman's rho correlation was used to see the correlation between iron status indicators and thyroid hormones. P-value less than 0.05 was considered statistically significant.

\section{RESULTS}

Out of the 200 participants, $41 \%(n=82)$ were from hilly region while $59 \%(\mathrm{n}=118)$ were from terai (plain) region. The mean age of the participating children was $10.13 \pm 1.66$ years. The overall mean $\pm \mathrm{SD} /$ median (IQR) of serum iron, TIBC and percentage transferrin saturation was $74.04 \pm 20.14$ $\mu \mathrm{g} / \mathrm{dl}, 389.38 \pm 23.7 \mu \mathrm{g} / \mathrm{dl}$ and $19.21(14.40,22.79)$ respectively. The mean $\pm \mathrm{SD}$ of serum fT3 and fT4 and median (IQR) of serum TSH concentrations was $2.87 \pm 0.52 \mathrm{pg} / \mathrm{ml}, 1.21 \pm 0.26 \mathrm{ng} / \mathrm{dl}$ and 3.03 (2.26, 4.34) $\mathrm{mIU} / \mathrm{L}$ respectively.

Though the median transferrin saturation was within reference range, $34 \%(n=68)$ of the children were iron deficient as indicated by low transferrin saturation. According to the geographical location, $28 \%(n=23)$ of the children from hilly region were iron deficient whereas $38.1 \%(n=45)$ from terai (plain) were iron deficient. The mean serum fT3 was higher in iron sufficient children than iron deficient children. There was no significant difference in mean serum fT3 and fT4 between iron deficient and iron sufficient children. Iron deficient children had higher median TSH than iron sufficient children but the difference was not statistically significant as shown in Table 1.

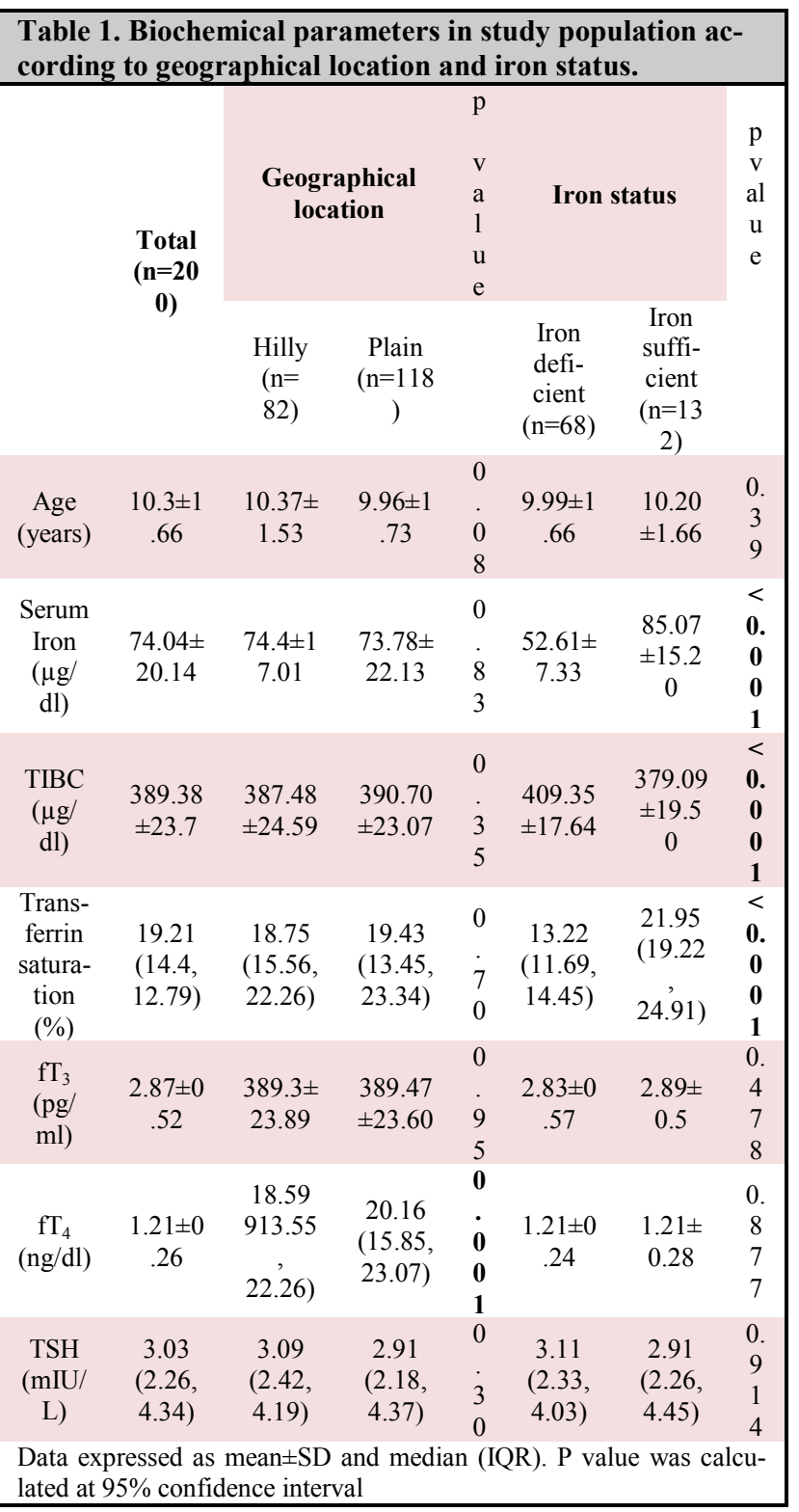

Majority of iron deficient children had normal thyroid function. Among 14 children with subclinical hypothyroidism 10 had sufficient iron nutrition while four of them were iron deficient as shown in Table 2. 


\begin{tabular}{|cccc|}
\hline \multicolumn{3}{|l|}{$\begin{array}{l}\text { Table } 2 \text { Thyroid function status in schoolchildren } \\
\text { according to iron status. }\end{array}$} & \multicolumn{2}{|c|}{ Iron status } \\
\hline Thyroid status & $\begin{array}{c}\text { Total } \\
(\mathrm{n}=200)\end{array}$ & $\begin{array}{c}\text { Iron defi- } \\
\text { cient } \\
(\mathrm{n}=68)\end{array}$ & $\begin{array}{c}\text { Iron sufficient } \\
(\mathrm{n}=132)\end{array}$ \\
Euthyroid & $\begin{array}{c}90 \% \\
(180)\end{array}$ & $91.2 \%(62)$ & $89.4 \%(118)$ \\
$\begin{array}{c}\text { Subclinical hypothy- } \\
\text { roid }\end{array}$ & $7 \%(14)$ & $5.9 \%(4)$ & $7.6 \%(10)$ \\
$\begin{array}{c}\text { Overt hypothyroid } \\
\text { Subclinical Hyperthy- } \\
\text { roid }\end{array}$ & $1.5 \%(3)$ & 0 & $2.3 \%(3)$ \\
Data expressed as percentage (number) & $1.5 \%(3)$ & $2.9 \%(2)$ & $0.8 \%(1)$ \\
\hline \multicolumn{4}{|l}{}
\end{tabular}

Spearman's rho correlation was applied between the thyroid parameters (fT3, fT4, and TSH) and iron status indicators (serum iron, TIBC and percentage transferrin saturation). There was a weak negative correlation between TSH and percentage transferrin saturation but was not significant $(\mathrm{r}=-0.098, \mathrm{p}=$ $0.168)$. Similarly weak negative and non-significant correlation was found between serum iron $(\mathrm{r}=$ $0.126, \mathrm{p}=0.076)$ and TIBC $(\mathrm{r}=-0.026, \mathrm{p}=0.717)$ with TSH.

\section{DISCUSSION}

Iron deficiency is common nutritional disorder prevalent in developing countries like Nepal. Overall, we found iron deficiency in $34 \%$ of the participating children. Iron deficiency is the commonest cause of anemia worldwide. Common causes of iron deficiency include inadequate dietary intake, greater demands and blood loss associated with parasitic infestation. Though among these causes hookworm infestation is believed to be the most important cause of iron deficiency in Nepal, particularly among the school aged children. ${ }^{6}$ All these factors should be considered along with other micronutrient deficiency in areas with high prevalence of iron deficiency.

Similar to our study, the prevalence of iron deficiency was high in different studies done on various part of Nepal. Khatiwada et al. reported iron deficiency in $43.6 \%$ of similar aged school children. ${ }^{7}$ Schulze et al. also reported high prevalence of iron deficiency among 6-8 years old children. ${ }^{5}$ In a study conducted in Kanti childrens' Hospital, Nepal, iron deficiency anemia was found in $65.25 \%$ of children below one year, $59.44 \%$ in $2-$ 4 year age group and $47.93 \%$ in $5-14$ years age group. $^{8}$ We found higher prevalence of iron deficiency among children residing in plain belt in comparison to the hilly region. Similarly, Kathiwada et al. also found higher prevalence of iron deficiency in plain region in comparison to hilly region. ${ }^{9}$ The difference in the prevalence of iron deficiency should account the different age groups, geographical location, and dietary patterns and more importantly the indices used to define iron deficiency.

In the present study we found thyroid dysfunction among $10 \%$ of the school children. Subclinical hypothyroidism was the most common thyroid dysfunction. Higher prevalence of thyroid dysfunction among school children was also reported by Khatiwada et al. ${ }^{7}$ and Chaudhari et al. ${ }^{10}$ We didn't find significant difference between thyroid function parameters in iron deficient and sufficient children. Study done in various part of world in different age groups by Hashemipour et al. ${ }^{11}$, Aziza et al. ${ }^{12}$ and Yavuz et al. ${ }^{13}$ also found no significant difference between thyroid hormones with different iron status indicators. In contrast to our finding Martinez-Torres et al. ${ }^{14}$ reported 10\% lower T3 levels in iron deficient subjects when compared to iron-replete subjects. Significant decreased T3 and T4 levels in iron deficient subjects was found by Beard et al. ${ }^{15}$ In our study no significant correlations was found between the iron status indicators and thyroid hormone level. Our finding was in accordance with study done by Wolde-Gebriel et al. ${ }^{16}$, Yavuz et al. ${ }^{13}$ and Hashemipour et al. ${ }^{11}$ in various parts of the world.

It is generally believed that iron deficiency adversely affects the physiology of thyroid and impairs thyroid hormone metabolism. Thyroid hormones increase iron absorption and incorporation into erythrocytes, whereas iron deficiency impairs thyroid hormone synthesis and metabolism. ${ }^{2}$ Though iron is required for the thyroid hormone synthesis and metabolism, it did not seem to effect the thyroid hormone metabolism to significant extent in the studied population. In most of the studies showing the significant difference in the thyroid function parameters and different iron status, comparative cross sectional or follow up studies were carried out taking iron deficient cases and iron sufficient controls. In those studies, iron status was assessed using more sensitive and accurate markers and done in populations of older age groups. There are multiple reasons for abnormal thyroid function. It is necessary to elucidate the roles of iodine deficiency, goitrogens, possible trace elements and vitamin A deficiencies. Thyroid antibodies was also not assessed in the population which might contribute to thyroid dysfunction seen in the studied population.

\section{CONCLUSIONS}

The prevalence of iron deficiency is high among children of eastern Nepal. Thyroid function 
parameters didn't significantly correlated with iron status indicators in the studied population. Only few cases of thyroid dysfunction were seen among iron deficient children but the exact causal effect association could not be ascertained as multiple factors may be associated with thyroid disorders.

\section{REFERENCES}

1. Zimmermann MB, Hurrell RF. Nutritional iron deficiency. The Lancet. 2007;370(9586):51120.

2. Zimmermann MB, Köhrle J. The impact of iron and selenium deficiencies on iodine and thyroid metabolism: biochemistry and relevance to public health. Thyroid. 2002;12 (10):867-78.

3. Hess SY, Zimmermann MB, Arnold M, Langhans W, Hurrell RF. Iron deficiency anemia reduces thyroid peroxidase activity in rats. The Journal of nutrition. 2002;132 (7):1951-5.

4. Dillman E, Gale C, Green W, Johnson DG, Mackler B, Finch C. Hypothermia in iron deficiency due to altered triiodothyronine metabolism. American Journal of PhysiologyRegulatory, Integrative and Comparative Physiology. 1980;239(5):R377-R81.

5. Schulze KJ, Christian P, Wu LS-F, Arguello $\mathrm{M}$, Cui $\mathrm{H}$, Nanayakkara-Bind $\mathrm{A}$, et al. Micronutrient Deficiencies Are Common in 6to 8-Year-Old Children of Rural Nepal, with Prevalence Estimates Modestly Affected by Inflammation. The Journal of nutrition. 2014;144(6):979-87.

6. F Curtale RT, Y Vaidya, R Pokheral, R Guerra. Intestinal heliminths and risk of anaemia among Nepalese children. Panminerva Med. 1993;35(3):159-66.

7. Khatiwada S, Gelal B, Baral N, Lamsal M. Association between iron status and thyroid function in Nepalese children. Thyroid research. 2016;9(1):2.

8. Baral M, Sharma P, Khetan B. Nutritional iron deficiency anaemia prevalence at Kanti children's' Hospital. Nepal Paediatric society Journal. 1985;4(2):101-4.

9. Khatiwada S, Lamsal M, Gelal B, Gautam S, Nepal AK, Brodie D, et al. Anemia, iron deficiency and iodine deficiency among

\section{ACKNOWLEGEMENT}

We kindly acknowledge Binaytara foundation for providing financial support through Binaytara foundation Medical research Grant 2015.

\section{Conflict of Interest: None}

Nepalese school children. The Indian Journal of Pediatrics. 2016;83(7):617-21.

10. Chaudhari RK, Gelal B, Brodie DA, Baral N. Thyroid function and urinary iodine status in primary school age children of the hills and the plains of Eastern Nepal. Indian pediatrics. 2012;49(4):332-33.

11. Hashemipour M, Soheilipour F, Keshteli AH, Siavash M, Amini M, Kelishadi R. Association between serum ferritin and goitre in Iranian school children. Journal of health, population, and nutrition. 2010;28(2):137.

12. Azizi F, Mirmiran P, Sheikholeslam R, Hedayati M, Rastmanesh R. The relation between serum ferritin and goiter, urinary iodine and thyroid hormone concentration. International journal for vitamin and nutrition research. 2002;72(5):296-9.

13. Yavuz Ö, Yavuz T, Kahraman C, Yeşildal N, Bundak R. The relationship between iron status and thyroid hormones in adolescents living in an iodine deficient area. Journal of Pediatric Endocrinology and Metabolism. 2004;17 (10): 1443-50.

14. Martinez-Torres C, Cubeddu L, Dillmann E, Brengelmann GL, Leets I, Layrisse M, et al. Effect of exposure to low temperature on normal and iron-deficient subjects. American Journal of Physiology-Regulatory, Integrative and Comparative Physiology. 1984;246 (3):R380-R3.

15. Beard JL, Borel M, Derr J. Impaired thermoregulation and thyroid function in irondeficiency anemia. The American journal of clinical nutrition. 1990;52(5):813-9.

16. Wolde-Gebriel Z, West CE, Gebru H, Tadesse A-S, Fisseha T, Gabre P, et al. Interrelationship between vitamin $\mathrm{A}$, iodine and iron status in schoolchildren in Shoa Region, central Ethiopia. British journal of nutrition. 1993;70 (2):593-607.

Citation: Thapa S, Lamsal M, Chaudhari RK, Gelal B, Sah SK,Kunwar S,Baral N.Impact of iron status on thyroid function: A community based cross sectional study in Eastern Nepal. JCMS Nepal. 2019;15(1):18-21. 